\title{
Synthesis and Free-Radical Thiilation (Addition of Thiophenols) of Unsaturated Cyclic Acetals
}

\author{
Farida Yusifli ${ }^{1}$, Gafar Ramazanov ${ }^{1}$ and Abasgulu Guliyev ${ }^{2}$ \\ 1. Sumgait State University, 124 S. Vurgun, Sumgait, Az5004, Azerbaijan \\ 2. Institute of Polymer Materials of Azerbaijan National Academy of Sciences, 124 S.Vurgun, Sumgait, Az5004, Azerbaijan
}

\begin{abstract}
The synthesis of a series of unsaturated 4-methylene-1,3-dioxolanes has been realized and the addition of thiophenol to the synthesized compounds in the presence of radical initiators has been carried out. It has been established the behavior of the addition reaction both with opening of dioxolane cycle and without it. The influence of nature of substituents of $\mathrm{C}_{2}$-carbon atom of dioxolane cycle, ratio of the initial reagents and temperature on direction of the addition reaction has been studied. The adducts obtained as a result of the addition reaction have a linear and cyclic structure, which have been established by data of the chemical and spectral analyses. It has been found that the ratio dioxolane compound: thiophenol, reaction temperature and nature of the functional substituent influences on quantity of these adducts.
\end{abstract}

Key words: Methylenedioxolane, thiophenol, adduct, thiilation.

\section{Introduction}

The polymerization of cyclic monomers (cycloalkanes, cyclic ethers, acetals of esters, lactams, etc.) attracts special attention of researchers with the aim of creation of the new polymers with original structural links in the chain of macromolecules. The polymerization of such monomers depends on a number of factors, including activity of functional group in cycle, nature of the used catalyst, cycle size, etc. [1].

Recently there have been developed the new types of heterocyclic monomers polymerizing with cycle opening [2,3], as a result of which the polymers with new structural units and useful properties have been prepared.

Taking into account the above-mentioned ones, in this work by epichlorohydrin reaction with some ketones there have been synthesized 2-substituted-chloromethyldioxolanes (1-4), on the basis of which there have been synthesized 2-methyl-2-cyclopentyl-4-methylene-1,3-dioxolane

Corresponding author: Farida Yusifli, senior lab. assistant, doctoral student, research field: macromolecular chemistry.
(5),

2-methyl-2-cyclohexyl-4-methylene-1,3-dioxolane (6), 2-cyclopentylidene-4-methylene-1,3-dioxolane 2-cyclohexylidene-4-methylene-1,3-dioxolane (8) and free radical addition of thiophenol to them.

\section{Experimental}

The IR-spectra were taken on apparatus "Cary 630 FTIR" of firm Agilent Tecnologes (crystal ZnSe). The PMR-spectra were taken on Fourier spectrometer» (frequency $300 \mathrm{MHz}$ ) of firm "Bruker" in $\mathrm{CCl}_{4}$ solution, internal standard hexamethyldisiloxane, the chemical shifts of signals are presented in the scale $\delta$ (ppm). The purity of the synthesized compounds was determined by a method of gas-liquid chromatography on chromatograph LKHM-8MD.

$2.1 \quad$ Synthesis of 2-Methyl-2-Cyclopentyl-4-Chloromethyl-1,3-Dioxolan $e(1)$

Epichlorohydrin (370 g, 4 mol) constantly stirring, was added drop by drop to the solution consisting of methylcyclopentyl ketone (224 g, $2 \mathrm{~mol}$ ) and trifluoride boron etherate $(5.6 \mathrm{~g}, 0.04 \mathrm{~mol})$. The reaction 
temperature was maintained in the ranges of $35-40{ }^{\circ} \mathrm{C}$. After this, the reaction mixture was stirred for $3 \mathrm{~h}$ at room temperature. The excess of epichlorohydrin was distilled away, and then the reaction mass was distilled in a vacuum. The yield of purposeful product was $89 \%$, B.p. $=45 \quad{ }^{\circ} \mathrm{C} / 2 \quad \mathrm{~mm}$ merc.c. ${ }^{1} \mathrm{H}-\mathrm{PMR}-\delta(\mathrm{ppm}):\left(\mathrm{CDCI}_{3}\right) \quad 3.45-3.60 \quad(2 \mathrm{H}, \quad \mathrm{m})$, 3.25-4.20 (3H, m), 1.20 (3H, s), 0.90-1.16 (9H, m).

Analogously by condensation of epichlorohydrin with methylcyclohexyl ketone, cyclopentanone and cyclohexanone

2-methyl-2-cyclohexyl-4-chloromethyl-1,3-dioxolane (2), 4-chloromethyl-2-cyclopentylidene-1,3-dioxolane (3), 4-chloromethyl-2-cyclohexylidene-1,3-dioxolane have been respectively synthesized (4).

\section{2 \\ Synthesis}

of

\section{2-Methyl-2-Cyclopentyl-4-Methylene-1,3-Dioxolane}

Twenty-seven (27) $\mathrm{g}(0.5 \mathrm{~mol})$ of sodium methylate in DMF $(100 \mathrm{~mL})$ at room temperature constantly stirring, was added drop by drop to the solution consisting of $40.9 \quad \mathrm{~g} \quad(0.2 \mathrm{~mol})$ of 2-methyl-2-cyclopentyl-4-chloromethyl-1,3-dioxolane in DMF $(200 \mathrm{~mL})$. The mixture was stirred at the same temperature for $4 \mathrm{~h}$. Then water $(150 \mathrm{~mL})$ was slowly added to the reaction mixture, after which it was extracted with ether $(200 \mathrm{~mL})$. The organic layer was separated and dried with anhydrous $\mathrm{MgSO}_{4}$, the solvent was distilled away. The residue was distilled at low pressure. The yield of purposeful product

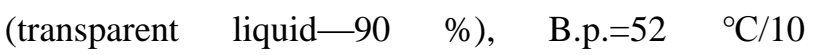
mm.merc.c., ${ }^{1} \mathrm{H}-\mathrm{NMR}-\delta$ (ppm.): $\left(\mathrm{CDCI}_{3}\right)$ 4.20-4.45 $(2 \mathrm{H}, \mathrm{m}), 3.80-4.20(2 \mathrm{H}, \mathrm{m}), 1.25(3 \mathrm{H}, \mathrm{s}), 0.92-1.16$ $(9 \mathrm{H}, \mathrm{m})$.

Analogously by interaction of 2-methyl-2-cyclohexyl-4-chloromethyl-1,3-dioxolane, 2-chloromethyl-2-cyclopentadien-1,3-dioxolane,

2-chloromethyl-2-cyclohexylidene-1,3-dioxolane with sodium methylate 4-methylene-2-methyl-2-cyclohexyl-1,3-dioxolane (6), 4-methylene-2-cyclopentadien-1,3-dioxolane 4-methylene-2-cyclohexylidene-1,3-dioxole (8) have been respectively synthesized.

\subsection{Addition of Thiophenol to Unsaturated Cyclic} Acetals

2.3.1 Addition of Thiophenol to 2-Methyl-2-Cyclopentyl-4-Methylene-1,3-Dioxolane

The addition of thiophenol to 2-methyl-2-cyclopentyl-4-methylene-1,3-dioxolane was carried out as follows: $2.8 \mathrm{~g}(0.025 \mathrm{~mol})$ of thiophenol, $3.36 \quad \mathrm{~g} \quad\left(\begin{array}{lll}0.02 & \mathrm{~mol})\end{array}\right)$ of 2-methyl-2-cyclopentyl-4-methylene-1,3-dioxolane and $0.03 \mathrm{~g}$ of $2.2^{\prime}$-azo-bis-isobutyronitrile (AIBN) ( $0.5 \%$ by weight of the initial components) as an initiator were placed in a one-chamber ampoule with capacity of $20 \mathrm{~mL}$. The ampoule was sealed and heated in a thermostat at $70{ }^{\circ} \mathrm{C}$ for 3 hours. At the end of the reaction, the mixture was cooled, the ampoule was opened and the contents were washed 3-4 times with $10 \%$ soda solution (for removal of excess of thiophenol) and extracted with ether. After drying over anhydrous $\mathrm{Na}_{2} \mathrm{SO}_{4}$, the ether was distilled away; the residue was distilled at low pressure. The yield of purposeful product (colorless oil) $-86 \%$, B.p. $=152-154{ }^{\circ} \mathrm{C} / 2$ mm.merc.c., ${ }^{1} \mathrm{H}-\mathrm{NMR}-\delta(\mathrm{ppm}):\left(\mathrm{CDCI}_{3}\right) 3.50(2 \mathrm{H}, \mathrm{d}), 3.75(3 \mathrm{H}$, $\mathrm{m}), 1.25(3 \mathrm{H}, \mathrm{s}), 0.9-1.16(9 \mathrm{H}, \mathrm{m})$ (cyclic adduct), $3.12(2 \mathrm{H}, \mathrm{s}), 4.18(2 \mathrm{H}, \mathrm{s}), 3.20(1 \mathrm{H}, \mathrm{m}), 1.30(3 \mathrm{H}, \mathrm{d})$, 0.9-1.16 (9H, m).

Analogously the addition of thiophenol to 4-methylene-2-methyl-2-cyclohexyl-1,3-dioxolane (6), 4-methylene-2-cyclopentylidene-1,3-dioxolane (7), 4-methylene-2-cyclohexylidene-1,3-dioxolane (8) has been realized.

\section{Results and Discussion}

The unsaturated 4-methylene-1,3-dioxolanes (5-8) have been synthesized by dehydrochlorination of chloromethyldioxolanes (1-4) in the presence of sodium methylate in DMF at room tempertaure. 


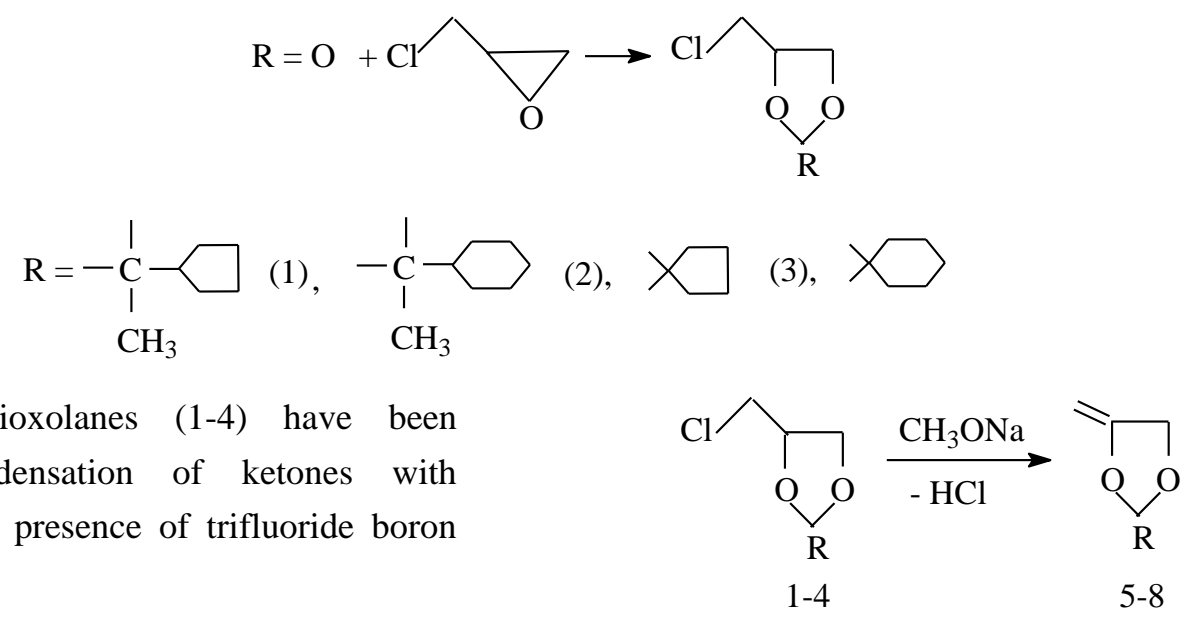

The purity of the compounds 1-4 has been determined by GLC-analysis and their composition and structure has been studied on the basis of data of IR- and PMR-spectra and also by elemental analysis. In the IR-spectra the intensive absorption bands presenting in the field of $650-670 \mathrm{~cm}^{-1}$ are referred to the valence vibrations of the chlorine atom. The ether bonds of dioxolane ring are appeared in the fields of $1,070-1,080 \mathrm{~cm}^{-1}$ and $1,100-1,120 \mathrm{~cm}^{-1}$.

In the PMR-spectra of the compounds 1-4 the protons of methylene, chloromethyl and methine groups as multiplet signal are appeared in the field of $\delta=4.06-4.45 \mathrm{ppm}, \delta=3.50-3.70 \mathrm{ppm}$ and $\delta=$ 3.20-3.45 ppm, respectively.

By dehydrochlorination of the synthesized chloromethyldioxolanes in the presence of sodium methylate in DMF solution at room temperature the corresponding unsaturated methylenedioxolanes have been obtained.

According to the chromatographical analysis the yields of the compounds 5-8 were sufficiently high. The structure of the synthesized compounds has been confirmed by data of IR- and PMR-spectroscopy and also by results of the elemental analysis.

In the IR-spectra of the compounds 5-8 there are characteristic absorption bands referring to the valence vibrations of $\mathrm{C}=\mathrm{C}$ bond in the field of 1,645-1,650 $\mathrm{cm}^{-1}$. The absorption bands in the fields of 1,080-1,090 and 1,110-1,130 $\mathrm{cm}^{-1}$ characterize the presence of ether bond of the dioxolane ring. In the PMR-spectra of the compounds 5-8 a ratio of integral intensities of signals at $\delta=4.30 \mathrm{ppm}$ refers to the protons of double bond and $\delta=3.8 \mathrm{ppm}$ characterizing the protons of $-\mathrm{OCH}_{2}$ group is $3: 1$. This has been possibly connected with signal overlapping of the proton of methylene group to broadened singlet of two olefinic protons (Table 1).

Table 1 Spectral characteristics of unsaturated cyclic acetals.

\begin{tabular}{|c|c|c|c|c|c|}
\hline \multirow[b]{2}{*}{ Compound code } & \multicolumn{5}{|c|}{ Chemical shifts of protons and proton-containing groups $(\delta, \mathrm{ppm})$} \\
\hline & $\mathrm{CH}_{2}=\mathrm{C}<$ & $-\mathrm{OCH}_{2}-$ & $y^{\mathrm{H}}{ }^{\mathrm{H}}{ }^{\mathrm{H}}$ & $\mathrm{H}]$ & $-\mathrm{CH}_{3}$ \\
\hline 5 & $4.30-4.50 \mathrm{~m}$ & $3.75-4.15$ & $0.90-1.16 \mathrm{~m}$ & - & $1.25 \mathrm{~s}$ \\
\hline 6 & $4.20-4.45 \mathrm{~m}$ & $3.80-4.20$ & $0.90-1.18 \mathrm{~m}$ & - & - \\
\hline 7 & $4.20-4.40 \mathrm{~m}$ & $3.75-4.20$ & - & $0.92-1.16 \mathrm{~m}$ & $1.25 \mathrm{~s}$ \\
\hline 8 & $4.25-4.50 \mathrm{~m}$ & $3.80-4.25$ & - & $0.92-1.16 \mathrm{~m}$ & - \\
\hline
\end{tabular}


To reveal the mechanism of radical homopolymerization of the synthesized unsaturated methylene dioxolanes 5-8 we have carried out the model reaction - addition of thiophenol (TPh) to these compounds. This reaction, first of all, makes it possible to determine the direction of attack of thiols radicals and to establish the microstructure of elementary links of the obtained polymers in their homopolymerization $[5,6]$. The addition reaction mechanism of TPh to the compounds 5-8 can be presented by the following scheme:

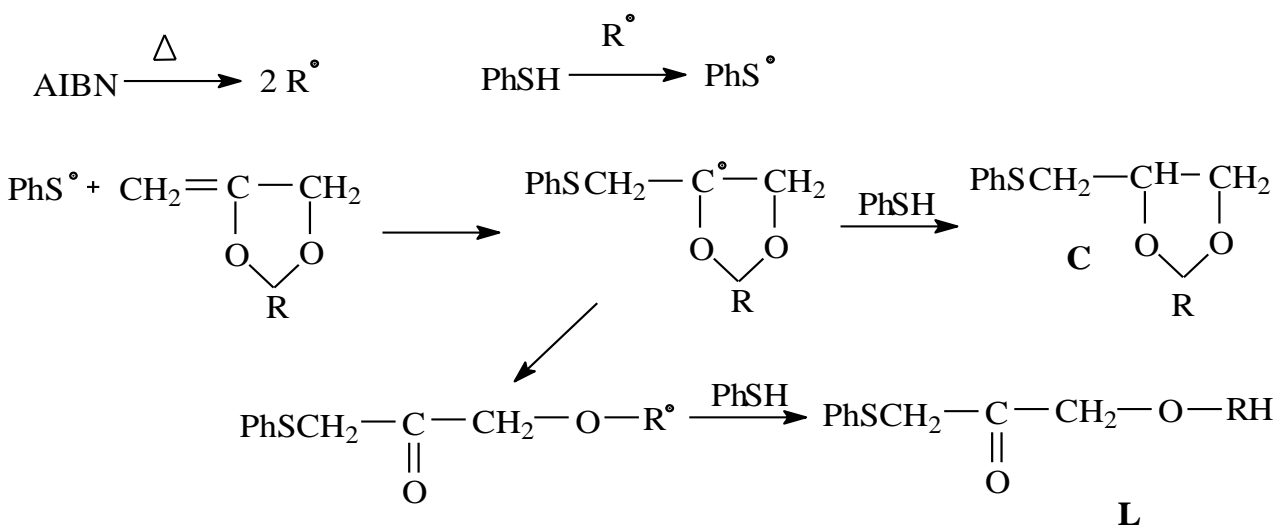

The addition of TPh to the synthesized monomers 5-8 was carried out at $70{ }^{\circ} \mathrm{C}$ in the presence of AIBN at various ratios of the initial reagents.

GLC-analysis of the reaction products showed that as a result of the addition of TPh to the compounds 5-8 a mixture of two products at various ratios is formed.

In the IR-spectra of the obtained adducts along with absorption bands characteristic for C-O-C-bond there are also the intensive absorption bands at $1,720 \mathrm{~cm}^{-1}$, characteristic for carbonyl group. This indicates that the addition of $\mathrm{TPh}$ to the compounds 5-8 proceeds both with dioxolane ring opening and without its opening. An analysis of data of the PMR-spectra of adducts also confirms the made assignments (Table 2). Since as a result of the addition reaction of TPh to these monomers it could be formed the cyclic and linear adducts (adducts $\mathrm{C}$ and $\mathrm{L}$ ), in the PMR-spectra of these adducts we should have observed the appearance of two groups of the proton signals of $\mathrm{SCH}_{2}$-fragment. In the cyclic adduct, the proton signals of $\mathrm{SCH}_{2}$-group should be appeared by doublet signals, while in the linear adduct the proton signals of these groups should be singlet character. Indeed, as shown by the analysis of PMR-spectra of the obtained adducts, the protons signals of $\mathrm{SCH}_{2}$-group in the cyclic adduct are appeared by doublet signal in the field of $\delta=3.50-3.70$ ppm, while the proton signals of $\mathrm{SCH}_{2}$-group in linear adducts are appeared at $\delta=3.20 \mathrm{ppm}$ as singlet. In addition, the proton signals of $\mathrm{H}_{2} \mathrm{C}-\mathrm{C}=\mathrm{O}$ group in the linear adducts are appeared as singlet signal at $\delta=4.20$ ppm.

Comparing the integral intensities of the proton signals of $\mathrm{SCH}_{2}$ groups in the cyclic and linear adducts, we found the ratio of the corresponding adducts.

It has been established that a ratio of adducts $\mathrm{C}$ and $\mathrm{L}$ depends on primary ratio of the initial reagents. For this reason the addition reaction of $\mathrm{TPh}$ to the compounds 5-8 was carried out at various ratios of the initial components. It has been revealed that at realization of the reaction with larger quantity of TPh $(4.2 \mathrm{~g}, 0.0375$ $\mathrm{mol}$ ), an increase of portion of the cyclic adduct over linear is observed. This indicates that in the initial stages of addition, the forming cyclic radical quickly separates the proton from the $\mathrm{TPh}$, since the concentration of the latter one in the reaction zone is greater. At realization of the reaction in excess of the compounds 5-8 the intermediately-forming cyclic radical has sufficient lifetime to regroup with cycle 
Table 2 Data of PMR-spectra of thiophenol adducts with unsaturated methylene dioxolanes.

\begin{tabular}{|c|c|c|c|c|c|c|c|}
\hline \multirow[b]{3}{*}{$\begin{array}{l}\text { Initial } \\
\text { compound }\end{array}$} & \multicolumn{7}{|c|}{ Chemical shifts of protons of groups $(\delta, \mathrm{ppm})$} \\
\hline & \multicolumn{4}{|c|}{ Cyclic adducts } & \multicolumn{3}{|c|}{ Linear adducts } \\
\hline & $\mathrm{SCH}_{2-}$ & $-\underset{1}{\mathrm{CH}}$ & 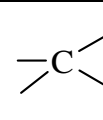 & $\mathrm{SCH}_{2-}$ & & $-\mathrm{O}-\mathrm{CH}-$ & $-\mathrm{C}-\mathrm{CH}_{3}$ \\
\hline 5 & $3.50, \mathrm{~d}$ & $4.10, \mathrm{~d}$ & $1.25, \mathrm{~s}$ & $3.15, \mathrm{~s}$ & $4.25, \mathrm{~s}$ & $3.15, \mathrm{~s}$ & $1.30, \mathrm{~s}$ \\
\hline 6 & $3.52, \mathrm{~d}$ & $4.12, \mathrm{~d}$ & $1.20, \mathrm{~s}$ & $3.25, \mathrm{~s}$ & $4.20, \mathrm{~s}$ & $3.20, \mathrm{~s}$ & $1.25, \mathrm{~s}$ \\
\hline 7 & $3.50, \mathrm{~d}$ & $4.10, \mathrm{~d}$ & - & $3.20, \mathrm{~s}$ & $4.20, \mathrm{~s}$ & $3.25, \mathrm{~s}$ & - \\
\hline 8 & $3.52, \mathrm{~d}$ & $4.12, \mathrm{~d}$ & - & $3.16, \mathrm{~s}$ & $4.25, \mathrm{~s}$ & $3.20, \mathrm{~s}$ & - \\
\hline
\end{tabular}

* Protons of cyclopentyl and cyclohexyl groups as multiplet signals are appeared in the field of 0.90-1.18 ppm.

Table 3 Composition of the reaction products of thiopheol with methylenedioxolanes.

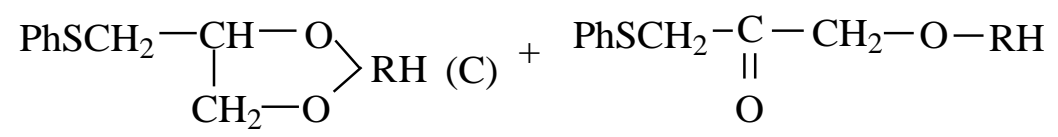

\begin{tabular}{|c|c|c|c|c|c|c|c|}
\hline \multicolumn{2}{|c|}{ Methylenedioxolanes } & \multicolumn{2}{|c|}{$\begin{array}{c}\text { Adduct of cyclic structure of } \\
\text { type C, } \%\end{array}$} & \multicolumn{2}{|c|}{$\begin{array}{c}\text { Adduct of linear structure of } \\
\text { type L, \% }\end{array}$} & \multicolumn{2}{|c|}{ Ratio C/L } \\
\hline Code & $\mathrm{R}$ & $\begin{array}{l}\text { According to } \\
\text { PMR-spectrum }\end{array}$ & $\begin{array}{l}\text { According to } \\
\text { GLC-analysis }\end{array}$ & $\begin{array}{l}\text { According to } \\
\text { PMR-spectrum }\end{array}$ & $\begin{array}{l}\text { According to } \\
\text { GLC-analysis }\end{array}$ & $\begin{array}{l}\text { According to } \\
\text { PMR-spectrum }\end{array}$ & $\begin{array}{l}\text { According to } \\
\text { GLC-analysis }\end{array}$ \\
\hline 5 & & 18 & 19 & 82 & 81 & 4.6 & 4.3 \\
\hline 6 & & 24 & 25 & 76 & 75 & 3.2 & 3.0 \\
\hline 7 & $\mathrm{CH}_{3}$ & 35 & 36 & 65 & 64 & 1.9 & 1.8 \\
\hline 8 & $\mathrm{CH}_{3}$ & 32 & 34 & 68 & 66 & 2.1 & 1.9 \\
\hline
\end{tabular}

opening. As a result of separation of the linear hydrogen radicals from $\mathrm{TPh}$, a linear adduct is formed.

The compositions of reaction products of TPh with compounds 5-8 are presented in Table 3.

As follows from the data in Table 3 , in a case of the compound 7 , it is observed a formation of the cyclic adduct in a large quantity in comparison with other methylenedioxolanes, but in all cases a quantity of the linear adducts prevails over a quantity of the cyclic adducts.

In a case of 2-cyclohexyl-2-methyl-4-methylene-1,3-dioxolane (6), a quantity of the cyclic adducts prevails somewhat.

These results can be explained by comparison of the stabilization levels of intermediately-forming cyclic and linear radicals.

Thus, the obtained results indicate that the radical addition of $\mathrm{TPh}$ to the unsaturated methylenedioxolanes proceeds both with dioxolane ring opening with formation of the linear and without cycle opening with formation of the cyclic adducts.

\section{References}

[1] Sanda, F., and Endo, T. 2001. "Radical Ring-Opening Polymerization." J. Polym. Sci., A, Polym. Chem. 39: 265-76.

[2] Nuyken, O., and Pask, S. D. 2013. "Ring-opening Polymerization-An Introductory Review." Polymers 5: 361-403. 
[3] Ramazanov, G. A., Shahnazarli, R. Z., and Guliyev, A. M. 2011. "Cyclopropyl-Substituted Methylenedioxolanes in the Reactions of Radical Addition and Polymerization. Fundamental and Applied Problems of a Science." Materials of VI International Symposium 2: 81-6.

[4] Ramazanov, G. A. 2003. "Synthesis of Cyclopropane-Containing Methylene-1,3-Dioxolanes. SDU." Scienctific news, Sumgait 2: 30-3.
[5] Walling, Ch., and Heuser, E. 1966. "Free Radical Addition Reactions to Olefins with Formation of Carbon-Carbon Bonds." In Collection of Organic Reactions. Moscow: Mir, 103-69.

[6] Guliyev, A. M., Ramazanov, G. A., Gasanova, S. S., and Nefedov, O. M. 1984. "Some Free Radical Reactions of Allyl Ether of 2-Vinyl-2-Methylcyclopropane Carboxylic Acid." Izv. AN SSSR, seriya khimicheskaya 12: 2729-31. 